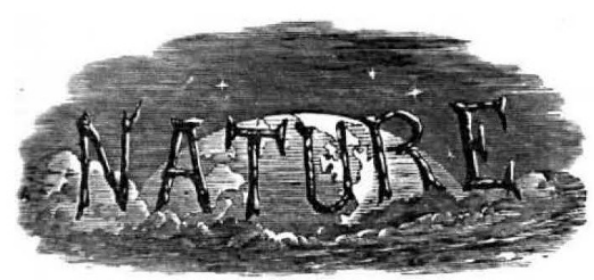

SATURDAY, SEPTEMBER 30, I922

\title{
The Protection of Inventions: An Empire Patent.
}

COMMON legislative action among the constituent parts of the British Empire would materially strengthen the bond which unites the peoples to one another and to the motherland. When, in addition, increased productiveness, lessening of cost, and . simplification of procedure are its accompaniment, and when general expediency points to the special course prescribed by it, few voices could well be heard in opposition. For many years a dream of politicians and reformers, manufacturers and inventors, has been the granting of a single patent to an inventor which, effective throughout the British Dominions, would give adequate protection without the necessity of securing patents from each of the constituent countries of the Empire. To obtain this wide measure of protection, an inventor, at the present time, must make not less than forty-six separate applications at a cost in official fees of more than three hundred pounds. Further, if protection be desired for the full periods which the respective laws permit, an additional sum of twelve hundred pounds and more must be forthcoming; and to this sum there is to be added the cost of the highly skilled preparation of the necessary documents, a formidable item which alone may amount to as much as the official fees for the applications. Now, if it were genuinely believed by all classes that the stimulation of invention results in greatly increased production, and that trouble and outlay in that direction are amply repaid, expenditure by governing bodies would no longer be deemed speculative, but would be looked upon as a sure and certain investment to be welcomed on all hands.

Although there is much to be urged in favour of this belief, possibly to the point of conviction, many reasons may be adduced for its non-acceptance by the authorities. The reasons, however, need not be specified, for the fact remains that hitherto there has been no such consensus of opinion as to lead the separate law-making bodies to common action and, through simplification of procedure and great reduction in cost, to encourage the inventor to successful effort within the territories of the several legislatures. Yet until the year $185^{2}$ it was the practice in this country to issue a single patent which was co-extensive in its operation with the whole of the Colonies, and in the Patent Law Amendment Act of that year a similar power was reserved. Although this power was not employed, for, in fact, no extensions were made, the reservation in the Act secured a practical result. It set on foot a series of inquiries by the Government, and led India and the Colonies to pass various patent

Telegraphic Address: PHUSIS, LONDON. Telephone Number: GERRARD 8830.

NO. 276 I, VOL. IIO] 
acts and ordinances. Simultaneously with the demand in the 'sixties of last century for the total abolition of patents, opinion was hardening upon the desirability for the extension of a patent to countries other than that in which it originated. In the Patents Act of $188_{3}$, which replaced the Act of $185^{2}$, no power was given for extending the territorial limit of a patent; nor in the Acts which now govern patents in this country is any such power present. In spite of much. sporadic agitation, no practical steps were taken for a patent of the United Kingdom to become operative in India, the self-governing Dominions, the Colonies, and Protectorates. This invoked Sir Robert Hadfield to say that "It is a crying shame that in a great Empire like ours we do not have one Empire Patent to cover the whole of our Dominions."

Although many societies and various learned bodies had discussed the question and emphasised the need of an Empire Patent, and, from time to time, had made representations to Government, officialdom appears to have been deterred by inherent difficulties in the production of an acceptable scheme. It had not perceived the possibility of formulating a practical measure to satisfy the justifiable aspirations and fair demands of inventors. But steady pressure and persistent endeavour are meeting with reward, for there are now indications of Governments treating seriously the proposals for an Empire Patent. A notably important advance was made in I92 I a conference of Prime Ministers and representatives of the United Kingdom, the Dominions, and India, when a memorandum, prepared in the Board of Trade, was discussed by a special committee. The conference agreed with the recommendation of its committee that representatives of the Patent Offices of His Majesty's Dominions should sit in London to consider the practicability of an Empire Patent. Accordingly sittings were held in June last, and a report of the conference has since been published. ${ }^{1}$

The report is not for popular reading; indeed in the main it is highly technical, and in its entirety can be understood only by those to whom the details of patent law and practice are of everyday concern. Further, its importance and significance are not to be measured simply by what it states expressly, since its implications and inferences must be gathered before its true import can be realised.

The discussion at the conference ranged round the present situation of affairs; the desirability for an Empire Patent; various schemes for obtaining the Patent and their practicability; and alternatively the possibility of rendering uniform the patent laws

1 British Empire Patent Conference. Report of the Conference held at the Patent Office, London, from. I2th June I922 to the 23rd June r922. avo. Pp. 28. (London: H.M. Stationery Office.) Is. net.
1s. throughout the Empire. The conference, while emphasising the importance of the preservation of the autonomy of the self-governing Dominions and of India, and insisting upon the rights and facilities at present enjoyed by inventors, concluded that an Empire Patent is desirable. Five schemes of the many that had been brought to notice were selected for special examination, the conference taking for its basis a memorandum prepared by the Comptroller General of Patents in r9r9. A few particulars of these schemes are set out in the report. Looking over these, it is apparent that for each much can be urged. In one, it may be, large expenditure is involved, although the advantages to be secured are great; in another, expenditure is comparatively small, with corresponding diminution in beneficial results. That difficulties will be encountered whatever scheme may ultimately be adopted is well known, but so far as can be judged, no such difficulty will be met as cannot be surmounted in the presence of a spirit of give-and-take, a spirit which must permeate the various legislatures and governing bodies before a uniform plan of action can be agreed upon.

According to one of the schemes, there is to be established a single central patent office for the issue of grants which should be operative throughout the Empire, local patent offices being abolished. This scheme was not approved, "having regard to practical difficulties," the chief of which were the distance apart of the units of the Empire and the loss of time which accordingly would be involved in transacting the necessary business. Another scheme contemplated the retention of local patent offices from which the usual territorial patents would issue, the issue taking place without examination into the novelty of the inventions to be protected. In addition, a central office would be established for the recording of the local patents and for their resultant extension to the Empire. The central office on being called upon by its patentees would also undertake a limited examination for novelty, and when the patent specification was suitably amended as a result of the examination, a note would appear that the examination had thus taken place. This scheme was not recommended, owing, it would seem, to the resulting abolition of the existing compulsory examination into novelty. The third scheme entailed the granting of Empire Patents in each self-governing Dominion and in India, each office being fully equipped with the registers and material necessary for the examination into novelty. In view of the expense and difficulty involved in setting up the offices and of the uncertainty as to the quality and value of the patent so granted, the conference found the scheme to be wholly impracticable. According to the "Preferred

$$
\text { NO. } 276 \text { I, VOL. IIO] }
$$


Scheme," a scheme which the conference recommended for adoption in the future, local patent offices are to be retained, each performing its present functions. There is also to be a fully organised central office for the detailed examination of applications for patents, the examination to include an extended search for novelty, the office eventually issuing the Empire Patents. But to make a patent operative in any country, registration in that country is compulsory, the registration being open to opposition if the local law provides for opposition to the granting of a patent.

By a "Provisional Scheme," which is recommended for immediate adoption and for continuation until the "Preferred Scheme" can be introduced, the grant of a patent in the United Kingdom carries with it the right to registration in any desired country of the Empire, the act of registration extending the grant to that country. But here, again, before the registration is made, it is open to opposition, if opposition to local grants is permitted by the local law.

Manifestly, whatever scheme came to be adopted by the separate legislatures or law-making bodies, much mutual adjustment of substantive and adjective law would be required. Some of these necessary adjustments were discussed at the conference, and suggestions emanating therefrom appear in the report. None appears to be of such a character as to be outside the bounds of practicability. But to review those subjects which call for adjustment, and to discuss the opinions on these and other points expressed at the conference, would require for each a monograph. From the report it is clear that an extremely small portion of the necessary amendments which the respective authorities would be called upon to make could have been discussed, bearing in mind that the conference held ten meetings only, and that it refused to admit oral evidence from outside, deciding that " no useful purpose would be served by hearing such evidence." There was, therefore, excluded from consideration the oral evidence that could have been given, for example, by the Chartered Institute of Patent Agents, a body which is continually in touch with the needs of inventors and conversant with the working and details of the various patent laws. Of necessity must the conference be looked upon as merely preliminary to attacking at close quarters the problem which it set out to solve.

On the unanimous selection of a scheme by each of the governing authorities, the next step will be for each to submit for general consideration the law, rules, and regulations which must be formulated in order that the selected scheme may be successfully put into operation. Moreover, it will be necessary to distinguish between the law to be applied when the patent is granted and the procedure for obtaining the patent. It will also be found that, in endeavouring to secure a basis for action, the task will be the easier by reason of the large majority of the patent laws of the Dominions having copied the law of the United Kingdom, and of the ultimate Court of Appeal for the Empire being the Judicial Committee of the Privy Council.

In the preparation of a scheme for general adoption it is to be hoped that the authorities will not continue to ignore oral evidence from outside bodies; to do so will be to court failure. Procedure for obtaining a patent and the law and rules relating to patents are so intricate that none but those who are in daily contact with such matters and have learned in the hard school of experience the needs of inventors on one hand and the reasonable requirements of the public on the other, can be expected to produce a scheme which, satisfactory to all parties, can be put into operation without friction, much change in procedure, or extensive amendment of existing laws.

There is no reason to suppose that, if all parties are -determined to produce an Empire Patent, the adjustment of conflicting opinions cannot be made nor suitable machinery devised. The result undoubtedly would be to the advantage of all inhabitants of the Homeland and of His Majesty's Dominions beyond the Seas, whether as inventors, manufacturers, or users. It remains, therefore, for the public to urge expedition upon the authorities, or it will be met with the charge of apathy, a plea which so often saves the situation where officials are concerned.

A word or two is to be said in respect of the charge for a copy of the report. In pre-war days, each copy of this small octavo would have been sold for $3 d$. or $4 d$., and the edition promptly exhausted with a consequent wide-spread dissemination of its information. For each copy of this edition of five hundred, however, one shilling is required, a charge which scarcely makes for extensive circulation. The wider the public that the report reaches, the greater chance of a definite outcome of its suggestions, while, at the same time, by the lowering of the price the probability of the recovery of the cost of the edition would not be appreciably lessened.

\section{Industrial Physics.}

A Dictionary of Applied Physics. Edited by Sir Richard Glazebrook. (In 5 volumes.) Vol. I : Mechanics, Engineering, Heat. Pp. ix + 1067. (London: Macmillan and Co., Ltd., I922.) 3l. 3 s. net.

$\mathrm{T}$ years to come the publication of this monumental 1 work will rank as one of the milestones in British applied science. If argument were needed, none more
NO. $276 \mathrm{I}$, VOL. IIO] 